\title{
ESTÁGIO DE DOCÊNCIA EM QUÍMICA: UM ESTUDO DOCUMENTAL SOBRE A CONSTRUÇÃO DE SABERES PROFISSIONAIS NA EDUCAÇÃO BÁSICA
}

\author{
Carlos Ventura Fonseca * \\ Charles Silveira Nunes**
}

Resumo: Este trabalho busca relatar e problematizar os aprendizados decorrentes das ações de um professor estagiário, no âmbito de uma atividade de ensino do curso de Licenciatura em Química da Universidade Federal do Rio Grande do Sul, tendo como principais referências teóricas as ideias de autores como Tardif e Nóvoa. O estágio foi supervisionado e realizado em uma escola pública estadual da capital gaúcha, em duas turmas de $1^{a}$ série do ensino médio. Trata-se de um estudo qualitativo exploratório, baseado em uma única fonte documental (o relatório final produzido pelo estagiário), de modo que foi realizada a análise de conteúdo da produção textual citada. Os resultados apontaram a ocorrência de quatro movimentos formadores de grande importância para a construção de saberes profissionais: observações do espaço escolar (fatores materiais, sociais, ambientais, econômicos, dentre outros), estudo de referenciais teóricos (envolvendo material didático, avaliação, resolução de problemas e modelos de ensino de Ciências da Natureza), regência de classe e construção de reflexões pessoais do professor estagiário sobre o trabalho na sala de aula (incluindo aspectos como: conhecimento sobre os conteúdos a serem trabalhados, tato pedagógico e relação entre teoria e prática). Constataram-se, assim, diferentes aprendizagens do professor estagiário decorrentes de seu trabalho na Educação Básica, bem como os dados analisados reforçaram a relevância da adoção de relatórios de estágio como fonte documental de pesquisas que se debruçam sobre a formação inicial de professores.

Palavras-chave: Formação docente. Estágio de docência. Ensino de Química. Saber docente.

\section{Introdução}

O presente trabalho converge com a área de pesquisa educacional que se interessa pela formação inicial de professores de Química, considerando, como uma de suas bases estruturais, a ideia de que a profissão docente apresenta um panorama de incertezas, instabilidades e conflitos (em seu fazer cotidiano), requerendo conhecimento na ação e sobre a ação (SCHÖN, 1983). Nesse enfoque, o trabalho docente é visto como um processo complexo, que não pode ser controlado por sistematizações técnicas simplificadoras (DINIZ-PEREIRA, 2002).

Tal modelo, baseado em uma perspectiva chamada de racionalidade prática, tem sido adotado em diferentes contextos, inclusive no campo da formação de professores de Química

\footnotetext{
* Professor da Universidade Federal do Rio Grande do Sul, onde atua na Faculdade de Educação. E-mail: carlos.fonseca@ufrgs.br.

** Licenciado em Química pela Universidade Federal do Rio Grande do Sul. E-mail: charlesnun@ yahoo.com.br. 
(SANTOS, 2007; FONSECA, 2014; FONSECA; SANTOS, 2015, 2018). Partindo dessa visão, o professor é entendido como um profissional capaz de refletir, tomar decisões e criar no âmbito de sua ação pedagógica (SCHÖN, 1983, 1995). A atuação autônoma no magistério, nesse sentido, requer habilidades que possibilitem aos sujeitos dialogarem de forma reflexiva e crítica com o trabalho desenvolvido nos ambientes escolares (SANTOS, 2007).

Por outro lado, este trabalho também está alinhado com alguns ensinamentos de Nóvoa (2009), autor que critica os efeitos dos discursos que tratam da profissionalização dos professores, ao afirmar que estes apresentam pouca incidência sobre a condição de trabalho e o estatuto do magistério. Segundo o autor citado, o consenso sobre a formação docente apresenta a proposição dos seguintes processos: articulação da formação inicial com a formação em serviço, ao longo da carreira; atenção especial aos professores em início de carreira, em seus primeiros contatos com a escola; valorização do perfil reflexivo da docência e da formação baseada na investigação; importância do estímulo ao trabalho em equipe, às culturas colaborativas, ao acompanhamento e à supervisão dos professores etc.

Nóvoa (2009, p.27) propõe percursos formativos que poderiam efetivamente melhorar a realidade dos profissionais do magistério. Nessa proposta, os sujeitos estariam envolvidos em um modelo de formação estabelecido pelo estudo aprofundado de casos de ensino (sucesso/insucesso), pela análise coletiva de práticas pedagógicas e pelo envolvimento/compromisso social.

Adotam-se, ainda, elementos discutidos por Tardif (2002) para compor o quadro teórico deste trabalho. Esse autor tem em vista a perspectiva de que é na realização de um trabalho que se pode obter um domínio progressivo dos saberes necessários à sua realização. A aprendizagem do trabalho docente, por esse viés, não pode estar limitada ao aprofundamento de conhecimentos teóricos e técnicos preparatórios para o exercício profissional, devendo ser permeada por uma formação prática, que possibilite a experiência direta no campo de atuação do magistério (TARDIF, 2002, p. 57).

Conforme os apontamentos de Fonseca e Santos (2016), diferentes pesquisas contemporâneas analisam práticas e experiências da formação inicial de professores, destacando a compreensão da realidade da escola básica e a construção de conhecimentos relacionados ao ofício docente por parte dos sujeitos, estudantes de cursos de licenciatura (CAMARGO; NARDI, 2007; GIANOTTO; DINIZ, 2010; HILA, 2008; PINHEIRO; MEDEIROS; OLIVEIRA, 2010; \# Tear: Revista de Educação Ciência e Tecnologia, Canoas, v.8, n.1, 2019. 
ROSA; VEIT, 2011; SILVA; CARVALHO, 2012). As produções acadêmicas abordam dificuldades e desafios enfrentados pelos aprendizes (BEJARANO; CARVALHO, 2003; GIANOTTO; DINIZ, 2010), bem como problematizam questões relativas às ações de investigação, planejamento e avaliação relacionadas ao trabalho do professor em formação na Educação Básica (BARCELOS; VILLANI, 2006). O estágio supervisionado (no caso deste artigo, estágio de docência), entendido pela legislação brasileira como "ato educativo escolar supervisionado, desenvolvido no ambiente de trabalho, que visa à preparação para o trabalho produtivo de educandos que estejam frequentando o ensino regular" (BRASIL, 2008), tem sido explorado, na literatura acadêmica, como espaço-tempo privilegiado para a consolidação da teia de relações entre teoria e prática na formação docente (LIMA, 2001; FELÍCIO; OLIVEIRA, 2008; BACH; FONSECA, 2018; RODRIGUES; ARROIO, 2018; SILVA; MESQUITA, 2018).

Nesse contexto, a pesquisa ora apresentada objetivou investigar as práticas pedagógicas, aprendizagens e vivências de um professor em formação que foram constituídas no âmbito de atividades de estágio em ensino de Química (durante o segundo semestre letivo de 2017), do curso de Licenciatura em Química da Universidade Federal do Rio Grande do Sul (UFRGS). Destaca-se que o sujeito (autor do relatório) estava, na ocasião, realizando o segundo estágio obrigatório do curso (do total de três estágios supervisionados previstos na estrutura curricular vigente à época). No âmbito do Departamento de Ensino e Currículo da Faculdade de Educação, essa atividade de ensino é pensada conforme as características formativas mencionadas nos parágrafos acima, sendo que a carga horária desta é dividida em: 45 horas de regência de classe; 15 horas de observação do espaço escolar; 15 horas de atendimento individual com o orientador; 60 horas de encontros coletivos na universidade. Como fonte de dados, foi consultado o relatório final de estágio produzido pelo estudante. Os processos formadores, que foram registrados no documento em tela, abrangeram encontros coletivos e individuais com o professor-orientador, leitura e interpretação de textos que apresentaram referenciais teóricos relevantes para execução e planejamento do ensino de Química, observação do espaço escolar, regência de classe e construção de reflexões pessoais sobre as vivências na Educação Básica.

\section{Referenciais teóricos}

A discussão sobre o conjunto de saberes que fundamentam o trabalho do professor não é um tema novo, embora ainda muito presente na pesquisa educacional (ALMEIDA; BIAJONE, \# Tear: Revista de Educação Ciência e Tecnologia, Canoas, v.8, n.1, 2019. 
2007; FONSECA, 2014). Ao tratar dessa questão, Tardif (2002, p.60) propôs o estabelecimento de um modelo tipológico de análise relacionando os diferentes saberes às suas fontes de aquisição social e às formas pelas quais estes se integram às peculiaridades da profissão: saberes pessoais (trazidos pela bagagem de vida, família etc.); saberes da formação escolar anterior (advindos da escola primária, escola secundária etc.); saberes provenientes da formação profissional para o magistério (construídos na licenciatura, na universidade, na formação continuada etc.); saberes provenientes dos programas e livros didáticos usados no trabalho (oriundos do uso de ferramentas da prática docente); saberes provenientes de sua própria experiência na profissão, na sala de aula e na escola (obtidos na prática do trabalho e na socialização profissional).

Pode-se, assim, admitir que os saberes docentes sejam formados por uma "amálgama" originada da interpenetração dos saberes experienciais, disciplinares, curriculares e daqueles obtidos durante a formação profissional inicial (TARDIF, 2002, p.36). Por outro lado, segundo argumentos de Tardif e Lessard (2008), o fazer cotidiano do professor está organizado em função de sua carga de trabalho. A análise desse fator deve ter em vista dois interferentes: as condições oficiais prescritas e as exigências reais, ou seja, a forma como os professores lidam com suas necessidades reais.

Os autores citados glosam que algumas tarefas possuem duração legal bem determinada (tempo de cada período de aula, intervalos etc.), enquanto outras dependem da relação do professor com o trabalho (planejamento e correção de atividades, reuniões etc.). Além disso, afirmam que há muitos fatores que devem ser considerados na análise da carga de trabalho (quais sejam: materiais; ambientais; sociais; econômicos; tamanho das turmas; diversidade dos perfis discentes; tempo de trabalho; vínculo empregatício; as tarefas que extrapolam o ensino; exigências formais (turnos de trabalho, reuniões etc.); a experiência docente em lidar com a multiplicidade de fatores que atravessam seu ofício).

Para Nóvoa (2009), a discussão sobre as características necessárias ao magistério, ou para definir “o bom professor", não deve reduzir a prática profissional docente a um perfil comportamentalista (conectado a um conjunto de procedimentos técnicos claramente delimitados). Assim, o autor conjuga as dimensões pessoais e profissionais para fundamentar a composição da identidade docente, estabelecendo algumas disposições essenciais na definição desse profissional (NÓVOA, 2009, p. 30-31), conforme segue. 
a) Conhecimento sobre os conteúdos a serem trabalhados: para promover a construção de práticas que facilitem a aprendizagem dos alunos, é necessário conhecer bem aquilo que se ensina.

b) Cultura Profissional: é necessário o entendimento sobre os sentidos presentes na instituição escolar, conhecer as práticas e aprender a profissão no diálogo com os profissionais mais experientes.

c) Tato pedagógico: entender os cruzamentos do trabalho com as dimensões pessoais são necessidades do ato de educar, o que viabiliza o ato de relacionar-se e comunicar-se com os estudantes.

d) Trabalho em Equipe: necessidade de atuação conjunta para execução dos projetos educativos escolares.

e) Compromisso Social: promoção da aprendizagem com base em valores da inclusão social e da diversidade, compreendendo o sujeito no âmbito de sua comunidade e de sua realidade.

f) Relação Teoria e Prática: as práticas docentes são revestidas por componentes teóricos e metodológicos que originam a construção de um conhecimento profissional específico e singular.

Nóvoa (2009, p.35) refere-se ao trabalho docente como uma forma de transformação deliberativa, pois este "supõe uma transformação dos saberes, e obriga a uma deliberação, isto é, a uma resposta a dilemas pessoais, sociais e culturais". Com isso, executar a prática docente não é possível sem que haja a mobilização de conhecimentos teóricos, sem que o domínio de um determinado conhecimento seja vislumbrado em todas as suas dimensões e complexidades.

\section{Metodologia}

Foi realizado um estudo qualitativo exploratório (LÜDKE; ANDRÉ, 1986) baseado em uma única fonte documental (o relatório final produzido pelo estagiário). Ressalta-se que a adoção do estudo documental é caracterizada pela estabilidade da fonte de dados consultada, que fornece elementos capazes de descrever o contexto no qual esses dados foram originados (LÜDKE; ANDRÉ, 1986). Tendo em vista tais aspectos, foi concretizada a análise de conteúdo da produção textual citada (FRANCO, 2008). Realizada, em um primeiro momento, a leitura flutuante da íntegra do texto, posteriormente foram obtidas unidades de registro (frases ou \# Tear: Revista de Educação Ciência e Tecnologia, Canoas, v.8, n.1, 2019. 
parágrafos) que fossem representativas das visões do estagiário sobre as experiências formativas. Com isso, foram adotadas algumas categorias de análise do corpo textual produzido pelo futuro professor (algumas categorias emergentes dos dados e outras baseadas na literatura acadêmica da área de formação docente, conforme será posteriormente descrito), decorrentes de seu contato com o ambiente escolar e com a as aulas presenciais na universidade.

Partindo-se dessa perspectiva, o foco deste trabalho restringir-se-á a analisar quatro momentos abordados no relatório do estagiário, que se constituíram como capítulos do referido documento acadêmico: i) Observação do espaço escolar; ii) Momentos de estudos de referenciais teóricos para elaboração do planejamento das aulas a serem ministradas no ensino médio, cujas sínteses foram registradas por escrito; iii) Textos dos planejamentos de aulas; iv) Textos dos relatos reflexivos sobre as aulas ministradas pelo estagiário, construídos após a realização destas. Para fins de organização deste artigo, a próxima seção será apresentada no formato de três subseções, que vão explorar o texto do relatório que foi investigado.

\section{Resultados e discussões}

4.1 Primeiro foco investigativo: observações do espaço escolar

Nesta parte, envolvendo a análise de conteúdo do texto que descreve as observações que foram realizadas pelo sujeito, houve a adaptação de certas categorias descritas na literatura para dados correlatos aos que estão sendo pesquisados (BROIETTI; BARRETO, 2011). Tendo seguido um roteiro de observações fornecido pelo professor-formador, o estagiário, em seu relatório, inicialmente aborda a infraestrutura da escola (categoria OBS-A) e os detalhes de sua documentação oficial (categoria OBS-B). Nessa descrição (resumidas no Quadro 1), são citadas as instalações, as condições de sala de aula, biblioteca, recursos disponíveis, além de aspectos administrativos da instituição (uma escola pública estadual do município de Porto Alegre/RS).

Quadro 1 - Categorias de análise oriundas do período de observação

\begin{tabular}{|l|l|l|}
\hline Código & Categorias de análise & Fragmentos representativos textuais do relatório \\
\hline OBS-A & $\begin{array}{l}\text { Infraestrutura da } \\
\text { escola }\end{array}$ & $\begin{array}{l}\text { Pode-se definir que, em sua estrutura física, há a constituição de } \\
\text { dois pavilhões, sendo o primeiro com dois andares. No primeiro } \\
\text { pavilhão, andar inferior, há as salas de aula do curso normal } \\
\text { magistério e salas “funcionais” - secretaria, departamento de } \\
\text { recursos humanos e tesouraria, direção (incluindo vice-direção } \\
\text { e coordenação pedagógica) e sala dos professores (com cozinha } \\
\text { e banheiro); no andar superior estão os banheiros e as salas de } \\
\text { aula. O segundo pavilhão, embora seja no segundo andar ( pois, }\end{array}$ \\
\hline
\end{tabular}

\# Tear: Revista de Educação Ciência e Tecnologia, Canoas, v.8, n.1, 2019. 
devido às características do terreno, não há o primeiro), contém salas de aula, refeitório, espaço de convivência, biblioteca e pequena área de lazer/atividades físicas.

\begin{tabular}{|c|c|c|}
\hline & & $\begin{array}{l}\text { devido às características do terreno, não há o primeiro), contém } \\
\text { salas de aula, refeitório, espaço de convivência, biblioteca e } \\
\text { pequena área de lazer/atividades físicas. }\end{array}$ \\
\hline OBS-B & $\begin{array}{l}\text { Documentos oficiais } \\
\text { da escola }\end{array}$ & $\begin{array}{l}\text { O PPP da escola está estruturado desde a caracterização dos } \\
\text { aspectos físicos, administrativos e pedagógicos relacionados } \\
\text { com a escola até uma descrição e interação desses com } \\
\text { aspectos intrínsecos à mesma, embora muitas vezes não } \\
\text { aparentemente perceptíveis. Além de uma análise do cenário } \\
\text { atual, também são apresentadas projeções para o futuro, } \\
\text { especialmente através do plano de metas e ações. Além da } \\
\text { descrição do funcionamento relacionado à rotina de diversas } \\
\text { atividades, no PPP também é contemplado, através de uma } \\
\text { gestão democrática, o envolvimento dos alunos, seja por meio } \\
\text { do Grêmio Estudantil, dos conselhos de classe participativos } \\
\text { ou dos pais, através do COM (Círculo de Pais e Mestres). }\end{array}$ \\
\hline OBS-C & $\begin{array}{l}\text { Contato com pares } \\
\text { profissionais e } \\
\text { recepção no ambiente } \\
\text { escolar }\end{array}$ & $\begin{array}{l}\text { Sobre a participação/interação durante as minhas aulas, deixou } \\
\text { muito explícito, desde o início, que o professor titular tem por } \\
\text { costume acompanhar as aulas de estágio, estando presente na } \\
\text { sala de aula - ou na escola -, realizando alguma outra } \\
\text { atividade. Contudo, se eu preferisse que assim não } \\
\text { acontecesse, que o informasse previamente. Solicitou também } \\
\text { que eu encaminhasse antecipadamente os planos de aula para } \\
\text { ter ciência do que e como seria trabalhado - sem, em nenhum } \\
\text { momento, ter questionado qualquer item apresentado. }\end{array}$ \\
\hline OBS-D & $\begin{array}{l}\text { Postura pedagógica do } \\
\text { professor-titular }\end{array}$ & $\begin{array}{l}\text { Em relação a sua forma de conduzir as aulas, pude perceber } \\
\text { que apresenta excelente relação com os alunos e, de maneira } \\
\text { geral, grande dedicação ao seu trabalho - tanto que os } \\
\text { equipamentos utilizados no procedimento das aulas ( entre } \\
\text { eles: computador, projetor de imagens e caixa de som) são de } \\
\text { propriedade particular. Do ponto de vista da execução de sua } \\
\text { aula, emprega uma abordagem tradicional a partir de um eixo } \\
\text { conceitual, ou seja, a exposição de suas aulas apresenta relação } \\
\text { com fatos do cotidiano, contudo, como forma de } \\
\text { exemplificação. Questionado especificamente sobre esse } \\
\text { tópico durante a entrevista no período de observação, o mesmo } \\
\text { salientou que, especialmente para os alunos do ensino médio, } \\
\text { diferentemente do ensino fundamental, centra a grande maioria } \\
\text { de suas atividades na forma expositiva (mas com interações } \\
\text { com os alunos) porque percebeu, ao longo do seu período de } \\
\text { docência, que os próprios alunos assim preferem. }\end{array}$ \\
\hline OBS-E & $\begin{array}{l}\text { Perfil e carga de } \\
\text { trabalho do professor- } \\
\text { titular }\end{array}$ & $\begin{array}{l}\text { O professor titular das turmas em que foi realizado o estágio é } \\
\text { graduado em Química e possui mestrado. Atua na escola desde } \\
2011, \text { mesmo ano em que ingressou na carreira docente. É } \\
\text { responsável pelas turmas desde o } 6^{\circ} \text { ano do ensino } \\
\text { fundamental até o } 3^{\circ} \text { ano do ensino médio, com exceção do } 2^{\circ} \\
\text { ano, em suas vinte horas semanais. Também leciona outras } \\
\text { vinte horas por semana em uma escola estadual no turno da } \\
\text { manhã. }\end{array}$ \\
\hline OBS-F & Caracterização das & Cada turma possui oficialmente, conforme o registro de \\
\hline
\end{tabular}




\begin{tabular}{|c|c|c|}
\hline & turmas & $\begin{array}{l}\text { chamada, } 17 \text { alunos - logo, } 34 \text { no total. No entanto, há pelo } \\
\text { menos dois alunos de cada turma que não frequentaram as } \\
\text { aulas. A composição dessas turmas, ou seja, o perfil dos } \\
\text { alunos, é de adolescentes na faixa etária dos } 15 \text { aos } 16 \text { anos. } \\
\text { Nenhum é repetente do primeiro ano do ensino fundamental. } \\
\text { Muitos necessitam de condução para irem à escola, sendo o } \\
\text { transporte público, através de ônibus coletivo, o meio mais } \\
\text { usado - inclusive há alunos que precisam pegar mais de um } \\
\text { ônibus. } \\
\text { Das duas turmas, uma é composta por alunos remanescentes da } \\
\text { própria escola - com exceção de um ou dois - e outra é } \\
\text { integralmente composta por alunos advindos de outras escolas. } \\
\text { Percebeu-se que esse fato, por si, gera uma espécie de } \\
\text { segregação entre os alunos e, até mesmo, uma impossibilidade } \\
\text { de integração, uma vez que é nítida certa "disputa" por status } \\
\text { entre as turmas. Em relação a essa “'segregação intencional” } \\
\text { no planejamento da composição dessas duas turmas do turno } \\
\text { da tarde, é visível também a diferença do andamento das aulas. } \\
\text { Percebe-se que a turma } 114 \text { (oriunda de outras escolas) } \\
\text { apresenta maior dificuldade em relação à } 113 \text {. }\end{array}$ \\
\hline OBS-G & $\begin{array}{l}\text { Contato com } \\
\text { estudantes }\end{array}$ & $\begin{array}{l}\text { Ao conversar com os alunos e, até mesmo, com o professor } \\
\text { sobre esse fato de serem turmas reduzidas, foi-me informado } \\
\text { que, entre os motivos, estão a transferências de alunos para } \\
\text { outras escolas devido à mudança da sede, sendo que muitos } \\
\text { migraram para o período noturno por começarem a trabalhar. } \\
\text { Esse fato mostra um pouco sobre a característica } \\
\text { socioeconômica de muitos alunos, os quais apresentam } \\
\text { dificuldades financeiras, necessitando buscar trabalho durante } \\
\text { o período do ensino médio (acredito que uma realidade muito } \\
\text { diferente em relação à dos alunos da rede privada.). }\end{array}$ \\
\hline
\end{tabular}

Fonte: Elaborado pelos autores com base no relatório final do estagiário.

Nessa narrativa, fica explícita a observação que foi realizada sobre o perfil do professortitular e sua postura pedagógica (categoria OBS-D; categoria OBS-E). Nesse ponto, o estagiário destaca a formação do profissional, suas atribuições (turmas e carga de trabalho), o relacionamento com os estudantes, bem como a metodologia de trabalho (citando o modelo de ensino tradicional e a estratégia de aula expositiva). Ainda que de forma resumida, também é descrita a recepção do professor-titular ao estagiário (categoria OBS-C) no que tange às combinações para o acompanhamento do estágio.

O relatório consultado também enfoca o perfil das turmas que seriam interpeladas pelo estagiário (categoria OBS-F) e os primeiros contatos com os estudantes do ensino médio (categoria OBS-G). O texto, nessa parte, retrata casos de evasão escolar, perfil etário de estudantes, aspectos sociais e econômicos, composição das turmas em termos de sua 
escolaridade anterior e a ocorrência de dificuldades de aprendizagem. Os registros feitos pelo futuro professor mostram-se relevantes para que este possa pensar o contex to no qual trabalharia, tendo em vista metodologias e objetivos gerais a serem planejados.

Sublinha-se que as categorias descritas no Quadro 1 tendem a indicar a ocorrência, nas vivências de observação do estagiário, dos fatores (determinantes do trabalho docente) citados por Tardif (2002): fatores materiais e ambientais (OBS-A; OBS-B); fatores sociais e econômicos (OBS-G); fatores ligados ao "objeto de trabalho" (OBS-F); fatores de organização do trabalho do professor (OBS-E); exigências formais (OBS-C); forma como os professores lidam com todos esses fatores (OBS-D). Nesse sentido, destaca-se que a história pessoal de vida e os saberes universitários (TARDIF, 2002) tendem a não ser suficientes para que o professor tenha pleno domínio das especificidades das escolas, sendo necessária uma imersão no ambiente de estágio para essa construção, tal como descrita no relatório.

\subsection{Segundo foco investigativo: referenciais teóricos estudados}

Para esta parte da análise de conteúdo do texto do relatório, emergiram quatro categorias que envolvem aprendizagens e reflexões sobre: materiais didáticos (categoria $\mathrm{RT}^{1}-1$ ), avaliação (categoria RT-2), resolução de problemas (categoria RT-3) e modelos de ensino para a área de Ciências da Natureza (categoria RT-4). Isso foi possível porque houve, no âmbito das atividades de estágio, momentos de estudos e aprofundamentos envolvendo referenciais teóricos da área educacional durante as aulas presenciais na universidade, sendo que as conclusões elaboradas pelo estagiário foram registradas por escrito (estando presentes em um capítulo específico do relatório). Em um dos trechos do relatório, emergem entendimentos acerca dos materiais didáticos (categoria RT-1), com base no artigo de Santos (2007). Nessa discussão, o estagiário evoca argumentos favoráveis ao ato de o professor exercer sua autonomia produzindo materiais didáticos, considerando as concepções trazidas pelos estudantes de seu universo social (fragmento abaixo extraído do relatório):

De posse dessas características e frente a um cenário onde impera a rigidez de alguns materiais didáticos, surge a oportunidade de o professor autônomo desenvolver seus próprios trabalhos de ensino, cujo cerne está centrado nas concepções alternativas dos estudantes a partir da vinculação de seus conhecimentos prévios com os conhecimentos

\footnotetext{
${ }^{1}$ A sigla "RT" foi adotada para codificar as quatro categorias que emergiram do segundo foco investigativo. 
científicos. Dentro desse cenário é destacada a produção de material no formato de Unidades Temáticas (UTs), ou seja, um material compatível com os princípios e as orientações curriculares contemporâneas, mas que aborda conteúdos/conceitos de forma flexível a partir de um ou mais temas específicos.

No prosseguimento do fragmento acima, o texto do relatório passa a destacar questões relacionadas à avaliação (categoria RT-2) dos estudantes do ensino médio (avaliação e suas variações: mediadora, formal, informal, diagnóstica, pedagogia do exame, da aprendizagem etc.). Aqui, as reflexões do sujeito focalizam alguns conceitos trabalhados através do artigo de Lemos e Sá (2013), sendo o fragmento abaixo extraído do relatório:

Contribui na ampliação do referencial teórico acerca do conceito de avaliação e na ampliação das possibilidades de aplicação de forma mais apropriada de métodos avaliativos. No estágio I havíamos trabalho sobre esse tema, embora de maneira não muito aprofundada. Mas a principal mensagem que pude extrair foi a de não utilizar, ao longo do trabalho de docência, independentemente do período, uma única forma de avaliação - especialmente a tradicional, que visa a uma espécie de classificação dos alunos.

Outro ponto de destaque, no processo formativo do estagiário, foi o desenvolvimento do trabalho com a estratégia de ensino conhecida como resolução de problemas (categoria RT-3). O autor demonstra ter considerado importante a apropriação de alguns conceitos trazidos pela leitura e discussão do artigo de Prates-Junior e Simões-Neto (2015). Além disso, conforme mencionado no fragmento textual abaixo, dentre outras inspirações, os planejamentos realizados pelo professor em formação inicial dialogou teoricamente com conceitos discutidos no artigo de Fernandes e Megid-Neto (2012), trabalho que explora diferentes modelos de ensino para a área de Ciências da Natureza (categoria RT-4). Além disso, fica evidente a concepção do estagiário (ao interagir teoricamente com os artigos mencionados) de que, para se pensar os movimentos didáticos de uma aula de Química, devem-se levar em conta múltiplas visões sobre o ensino e a aprendizagem (fragmento abaixo extraído do relatório):

O texto apresenta diversas características e definições para exercícios e problemas. [...] $\mathrm{O}$ conhecimento adquirido com o estudo deste texto, em especial sobre soluçãoproblema, contribui de forma a ofertar-me uma ferramenta alternativa à tão conhecida abordagem tradicional. Trata-se de uma atividade onde os alunos necessitam construir um pensamento e raciocínio para resolução de um problema proposto, ou seja, são agentes mais ativos do processo. [...] A partir das apresentações das abordagens metodológicas no campo da docência indicadas por Fernandes e Megid-Neto (2012), pode-se considerar que este trabalho terá não exclusivamente uma única linha de ação, mas sim uma mescla entre elas. Sendo assim, não significa que uma abordagem mais tradicionalista, através de exposição na forma escrita ou oral, será totalmente omitida. A ideia é a complementação da aula como um todo através dos somatórios dos métodos didáticos, sabendo o momento mais adequado para cada um deles. 
As aprendizagens originadas nesse processo formativo, é possível supor, foram sendo construídas de modo que o estagiário conseguisse tornar mais abrangentes e seguros os enlaces teórico-práticos necessários para compor o planejamento das aulas que seriam desenvolvidas no ensino médio, elementos que, no entendimento de Tardif (2002), podem ser chamados de saberes provenientes da formação profissional para o magistério. Nesse contexto, o professor-estagiário planejou e conduziu um conjunto de atividades que englobou 33 aulas (33 períodos de 50 minutos), sendo que tais elementos são o tema de análise da próxima seção.

4.3 Terceiro foco investigativo: planejamento e reflexões sobre a regência de classe

Nesta parte do estudo, o foco é colocado sobre os planos de aula produzidos pelo sujeito em formação (resumo das atividades indicado no Quadro 2), bem como sobre as reflexões (relatos sobre os eventos da sala de aula) registradas após a realização de seu trabalho na escola. Consideram-se, aqui, categorias de análise pré-determinadas, com base no ideário de Nóvoa (2009), citado em seção anterior deste trabalho: categoria 1- Conhecimento sobre os conteúdos a serem trabalhados; categoria 2- Cultura Profissional; categoria 3- Tato pedagógico; categoria 4Trabalho em equipe; categoria 5- Compromisso social; categoria 6- Relação Teoria e Prática.

Quadro 2 - Síntese dos planos de aula para a $1^{\text {a }}$ Série do Ensino Médio

\begin{tabular}{|c|c|}
\hline Aulas & Atividades \\
\hline 01 e 02 & $\begin{array}{l}\text { Aula expositiva-dialogada, com uso de simulações (oriunda de um sítio eletrônico) } \\
\text { sobre átomos e trabalho em grupo. }\end{array}$ \\
\hline 03 e 04 & $\begin{array}{l}\text { Uso de problematização inicial e posterior aula expositivo-dialogada. Utilização de } \\
\text { vídeos, leitura e interpretação de artigos jornalísticos sobre mineração. }\end{array}$ \\
\hline 05 e 06 & Exercícios de revisão sobre os conteúdos trabalhados. \\
\hline 07,08 e 09 & Evento externo sobre a História da civilização (palestras). \\
\hline 10 e 11 & Jogo lúdico e aula expositivo-dialogada de retomada dos conteúdos. \\
\hline 12 e 13 & $\begin{array}{l}\text { Correção de exercícios e fechamento da atividade do evento externo, com discussão } \\
\text { sobre a relação da história com o conhecimento científico. }\end{array}$ \\
\hline 14 e 15 & $\begin{array}{l}\text { Resolução de problemas envolvendo soldagem e metais - (Problema } 01-\text { Fechado e } \\
\text { Quantitativo): Apresentação da proposta e formação dos grupos. }\end{array}$ \\
\hline 16 e 17 & $\begin{array}{l}\text { Resolução de problemas envolvendo soldagem e metais - (Problema } 01 \text { - Fechado e } \\
\text { Quantitativo): Apresentação oral das resoluções pelos grupos e fechamento expositivo- } \\
\text { dialogado conduzido pelo professor. }\end{array}$ \\
\hline 18 e 19 & Resolução de problemas envolvendo lixo eletrônico - (Problema $02-$ Aberto e \\
\hline
\end{tabular}




\begin{tabular}{|c|c|}
\hline & Qualitativo): Apresentação da proposta e formação dos grupos. \\
\hline 20 e 21 & $\begin{array}{l}\text { Resolução de problemas envolvendo lixo eletrônico - (Problema } 02-\text { Aberto e } \\
\text { Qualitativo): Grupos pesquisam no laboratório de informática. }\end{array}$ \\
\hline 22 e 23 & $\begin{array}{l}\text { Resolução de problemas envolvendo lixo eletrônico - (Problema } 02-\text { Aberto e } \\
\text { Qualitativo): Apresentação oral das resoluções pelos grupos e fechamento expositivo- } \\
\text { dialogado conduzido pelo professor. }\end{array}$ \\
\hline 24 e 25 & Breve discussão sobre ligação química (aula expositiva e dialogada). \\
\hline 26 e 27 & $\begin{array}{l}\text { Revisão geral dos assuntos trabalhados (aula expositiva e dialogada), com utilização de } \\
\text { exercícios. }\end{array}$ \\
\hline 28 e 29 & Avaliação escrita do $3^{\circ}$ trimestre letivo. \\
\hline 30 e 31 & Entrega da avaliação e correção (aula expositiva e dialogada). \\
\hline 32 e 33 & Avaliação escrita anual. \\
\hline
\end{tabular}

Fonte: Elaborado pelos autores com base nos planos de aula do relatório.

No que diz respeito à categoria 1 (Conhecimento sobre os conteúdos a serem trabalhados), os planos de aula deixam explícita a organização de aulas com os seguintes assuntos: átomos e elementos químicos (número atômico, número de massa, isótopos, íons); distribuição eletrônica e tabela periódica (períodos e grupos); relação entre mineração e tabela periódica; relação entre lixo eletrônico e tabela periódica; propriedades periódicas. Nos documentos analisados, houve estruturação correta do ponto de vista dos conceitos químicos previstos (havia espaço específico, nos planos de aula, nos quais o professor registrou com detalhes os conhecimentos que seriam estudados), evidência que denota o domínio satisfatório de conteúdos conceituais por parte do estagiário, muito provavelmente adequado às funções de um professor de Química do ensino médio.

No que se refere às categorias 2 (Cultura Profissional) e 4 (Trabalho em equipe), as evidências apontam que houve movimentos limitados de aprendizagem sobre a profissão docente com os professores que trabalhavam na escola em que foi realizado o estágio, excetuando-se a relação de proximidade com o professor titular de Química, responsável pela supervisão do estagiário. Foi relatada apenas uma situação de ensino de compartilhamento direto com outra colega de profissão (participação proposta pela professora de Sociologia e Filosofia dos estudantes de ensino médio em um evento sobre a História da Civilização, realizado durante as aulas 07, 08 e 09). As demais situações de contato profissional narradas pelo estagiário, em seu relatório, restringiram-se a conversas com o seu supervisor sobre detalhes do planejamento e do desenvolvimento das aulas de Química. Nesse ponto, o estágio mostrou-se um período pouco 
agregador em termos de diferentes visões e experiências diversas sobre a docência (situações que poderiam extrapolar a área de conhecimento estrita de atuação do sujeito).

Sobre a categoria 3 (Tato pedagógico), há vários indicativos de que o professor em formação buscou refletir sobre situações de comunicação variadas que ocorreram em suas aulas, dando indicativos da construção de seu relacionamento com os estudantes ao longo do período de regência. Essa multiplicidade de eventos descritos para a categoria 3, a partir da análise de conteúdo realizada sobre o texto investigado, revelou sete subcategorias que possibilitam uma visão mais abrangente e mais precisa sobre as aprendizagens do professor-estagiário (fragmentos textuais imbricados nessas situações estão mostrados no Quadro 3). O relatório investigado mostra que o contato professor-estudantes foi construído em situações de sala de aula que abordaram: motivos de falta às aulas (subcategoria T1); críticas discentes ao trabalho docente (subcategoria T2); diferentes orientações dadas pelo professor em relação aos procedimentos de sala de aula (subcategorias T3, T4 e T5); receptividade dos sujeitos em relação às atividades propostas (subcategoria T6); percepções do docente sobre aspectos disciplinares e andamento das atividades de aula (subcategoria T7).

Quadro 3 - Subcategorias que caracterizam aprendizagens/desenvolvimento do Tato Pedagógico

\begin{tabular}{|c|c|c|}
\hline Código & Subcategorias & Fragmentos representativos textuais do relatório \\
\hline $\mathrm{T} 1$ & Faltas & $\begin{array}{l}\text { Os alunos inicialmente argumentaram que não foi um ato planejado, mas } \\
\text { sim havia alguns que não estavam a fim de irem à aula no dia. Alguns } \\
\text { disseram que faltaram por algum motivo específico e deram a entender } \\
\text { que a falta coletiva poderia ter sido uma coincidência; Na sequência, } \\
\text { como uma forma de justificativa mais real (a partir da minha análise), os } \\
\text { alunos começaram a demonstrar os reais motivos de falta, ficando mais } \\
\text { evidente: (1) a carga horária extensa de química durante a semana - } \\
\text { chegando a ter } 06 \text { períodos. }\end{array}$ \\
\hline $\mathrm{T} 2$ & Abertura a críticas & $\begin{array}{l}\text { Falamos para os alunos que estamos totalmente abertos para aceitar } \\
\text { críticas, mas que iríamos argumentar contrariamente, caso fosse } \\
\text { necessário. Acredito que essa insatisfação por parte dos alunos seja } \\
\text { decorrência de diversos outros fatores para além de nossas aulas - entre } \\
\text { estes está uma certa resistência “natural”, criada pelos alunos, como } \\
\text { forma de retardar o processo de ensino-aprendizagem. Ficamos } \\
\text { praticamente todo o primeiro período com essa conversa, o que não } \\
\text { considero como uma perda de tempo. }\end{array}$ \\
\hline $\mathrm{T} 3$ & $\begin{array}{l}\text { Orientações de } \\
\text { trabalho }\end{array}$ & $\begin{array}{l}\text { Orientamos os alunos a realizarem as atividades em grupo, ou seja, a } \\
\text { realização e ajuda mútua. Poderiam, sem problema algum, dentro de suas } \\
\text { estratégias de ação, dividirem tarefas, desde que se interessassem, }\end{array}$ \\
\hline
\end{tabular}




\begin{tabular}{|c|c|c|}
\hline & & $\begin{array}{l}\text { mesmo que com menor ênfase, pelas atividades dos demais colegas, } \\
\text { delas participando. }\end{array}$ \\
\hline $\mathrm{T} 4$ & $\begin{array}{l}\text { Reforço sobre a } \\
\text { necessidade dos } \\
\text { procedimentos }\end{array}$ & $\begin{array}{l}\text { (...) a aula teve fortes características tradicionais, sendo os conteúdos } \\
\text { passados de forma expositiva no quadro. Mais uma vez também, mesmo } \\
\text { estando em recuperação anual, os alunos (de novo, maioria destes...) } \\
\text { insistiam em não copiar no caderno (ou na prova, ou em qualquer outro } \\
\text { material...). Chamei a atenção deles novamente sobre esse fato, dizendo } \\
\text { para aproveitarem o momento e estudarem em sala de aula, tentando } \\
\text { aprender determinados conceitos de forma a maximizar o tempo. }\end{array}$ \\
\hline $\mathrm{T} 5$ & $\begin{array}{c}\text { Acompanhamento } \\
\text { das tarefas } \\
\text { discentes }\end{array}$ & $\begin{array}{l}\text { A atividade autônoma de debate interno do grupo e construção do banco } \\
\text { de palavras estava sendo muito fortuita. Dessa forma, resolvi intervir e } \\
\text { comentar sobre algumas partes específicas contidas no livro do evento. } \\
\text { Exemplo: Alan Turing e códigos no quadro. Com essa intervenção houve } \\
\text { o ganho de atenção dos alunos. }\end{array}$ \\
\hline T6 & $\begin{array}{l}\text { Aceitação das } \\
\text { atividades de } \\
\text { aprendizagem }\end{array}$ & $\begin{array}{l}\text { É interessante fazer uma nota específica sobre o uso do simulado no } \\
\text { computador. Eu já havia usado este software específico, o PhET, de } \\
\text { forma individual e como “entretenimento“". Na sala de aula, quando } \\
\text { perguntado aos alunos sobre esse tipo de ferramenta, por exemplo, no } \\
\text { auxílio do processo de aprendizagem, grande parte esboçou de forma } \\
\text { positiva sua utilização - principalmente pela facilidade visual. Contudo, } \\
\text { nenhum deles havia até então visto ou utilizado algo do gênero e, pior, } \\
\text { não senti firmeza no tom de voz deles quando indagados se pretendiam } \\
\text { usar a plataforma como instrumento de estudo. }\end{array}$ \\
\hline $\mathrm{T} 7$ & $\begin{array}{c}\text { Aspectos } \\
\text { disciplinares }\end{array}$ & $\begin{array}{l}\text { Em relação aos aspectos conceituais, os alunos apresentaram bom } \\
\text { raciocínio desde o início, principalmente em relação às interações } \\
\text { eletrostáticas entre prótons e elétrons e sua relação com a transformação } \\
\text { de um elemento. No entanto, no que se refere aos aspectos atitudinais, } \\
\text { especificamente ao comportamento, um grupo de alunos estava muito } \\
\text { inquieto, com conversas entre si a todo o momento e o constante uso do } \\
\text { celular. Houve a necessidade de interrupções da aula. }\end{array}$ \\
\hline
\end{tabular}

Fonte: Elaborado pelos autores com base no relatório final do estagiário.

Com relação à questão do Compromisso Social (categoria 5), o texto do relatório não deixa maiores indicativos da preocupação do docente em formação com o perfil sociocultural dos estudantes interpelados pelo seu trabalho (ou suas comunidades), nem mesmo com valores explícitos de inclusão social ou diversidade (NÓVOA, 2009). Tal preocupação pode ter se manifestado de modo indireto, tendo em vista a proposição docente em discutir uma temática de interesse social e ambiental (soldagem e lixo eletrônico) durante as aulas que envolveram a resolução de problemas, mas as evidências ficam limitadas a esse aspecto. Nesse sentido, podese inferir que o estágio não colaborou suficientemente para a constituição de conhecimentos profissionais satisfatórios traduzidos em práticas docentes relacionadas à categoria mencionada.

No que concerne à categoria 6 (Relação Teoria e Prática), as evidências apontam que o 
trabalho realizado pelo estagiário promoveu, em boa medida, articulações relevantes entre as situações práticas da sala de aula e os referenciais teóricos educacionais que foram estudados durante o período de estágio (nos encontros coletivos ocorridos na universidade, bem como em outros momentos do curso de licenciatura). Há, nos planejamentos analisados, referências a diversos autores que tenderam a nortear o trabalho do professor de Química em formação, o que pode ser verificado na organização do conjunto de aulas conectadas por uma temática específica (SANTOS, 2007) e por atividades de resolução de problemas que foram protagonistas dos processos de ensino-aprendizagem (PRATES-JUNIOR; SIMÕES-NETO, 2015), dentre outras propostas que foram alocadas no Quadro 2.

Em especial, o estagiário demonstrou ter constituído maior aproximação teórica com a linha construtivista do ensino de Ciências da Natureza, tendo em vista o fato de que esse modelo entende a construção do conhecimento como um processo a ser realizado pelo aluno de forma individual ou coletiva, tendo o professor como um mediador das ações, com o papel de estimular o aluno a buscar o conhecimento (FERNANDES; MEGID-NETO, 2012). Há, ainda, certos traços do movimento de ensino conhecido como CTS (Ciência, Tecnologia e Sociedade), já que a conscientização sobre relações do contexto social com os conhecimentos científicotecnológicos da Química foram temas específicos das aulas ministradas, especialmente as que envolveram resolução de problemas (FERNANDES; MEGID-NETO, 2012).

Essas aproximações são citadas, no relatório, nos textos dos planejamentos, especificamente na parte que se refere à metodologia de cada aula. Ainda que o estagiário também tenha planejado/desenvolvido aulas expositivas (típicas do modelo tradicional de ensino), estas foram pensadas/realizadas em um contexto diversificado de práticas docentes, tendendo a fazer sentido para a continuidade das ações e colaborando para a construção do conhecimento dos estudantes de ensino médio.

No que diz respeito à avaliação (ainda no espectro de evidências textuais da categoria 6), a análise do relatório permitiu inferir que o professor em formação seguiu normativas da escola que foi campo de seu estágio (que exigiam provas trimestrais que classificavam os alunos pelo seu número de erros/acertos). Por outro lado, foi possível ao professor-estagiário estabelecer, ainda que parcialmente (em aulas que envolveram resolução de problemas), processos de avaliação mediadora (LEMOS; SÁ, 2013). Estes objetivaram diagnosticar, mediar e intervir nos processos de sala de aula que dificultavam a aprendizagem dos estudantes, possibilitando sua \# Tear: Revista de Educação Ciência e Tecnologia, Canoas, v.8, n.1, 2019. 
superação.

O conjunto de resultados obtidos permite a elaboração de algumas asserções de conhecimento em diálogo com a literatura contemporânea consultada. O primeiro ponto a ser destacado é a relevância do relatório do estágio de docência supervisionado como fonte de dados para pesquisa educacional (BROIETTI; BARRETO, 2011; BACH; FONSECA, 2018; RODRIGUES; ARROIO, 2018). Essa escolha tende a permitir o acesso a um registro escrito relativamente sistematizado de dados e reflexões desenvolvidas por professores em processo de formação inicial, ainda que as construções textuais dos sujeitos (que estão constituindo-se como docentes, em processo inicial de desenvolvimento profissional - em termos teóricos e práticos) apresentem limitações em termos da qualidade textual. Admitindo-se que os professores universitários, formadores dos estagiários, organizam momentos de aprofundamento teórico e debates sistemáticos sobre o conteúdo dos relatórios a serem produzidos nas atividades de estágio, pode-se inferir que tais documentos acadêmicos constituem-se como uma espécie de testemunho privilegiado das vivências profissionais e aquisições intelectuais desenvolvidas pelos aprendizes.

O segundo ponto que emerge dos resultados é a possibilidade, mediada por pesquisas que exploram os relatórios de estágio de docência, de problematizar a realidade da escola e de seus profissionais. Essas produções acadêmicas podem, à medida que constituam um movimento mais amplo nas diferentes áreas da formação docente, disseminar ideias e debates crescentemente úteis à formação inicial e continuada de professores. Há, nesse processo, potencial para desestabilizar visões negativas sobre o ambiente escolar e a cultura de trabalho na Educação Básica brasileira, promovendo reflexões que dotem os (futuros) professores de uma visão transformadora da realidade (RODRIGUES; ARROIO, 2018).

Isso não significa que tais estudos tenham o condão de melhorar, por si sós, o contexto das escolas e os problemas estruturais que dificultam o trabalho docente, mas que estes podem explicitar elementos da complexidade do contexto profissional do magistério, subsidiando movimentos de construção coletiva de alternativas práticas (articuladas, sempre, a teorias educacionais) e enfretamentos dos desafios em tela. Os resultados de investigações com esse caráter podem dar sustentação a processos formativos em diferentes cursos de licenciatura, hipótese que converge com o entendimento de Fonseca e Santos (2018, p.13) quando discorrem sobre os objetivos da formação inicial docente: 


\section{\#tear}

Acreditamos que os cursos de licenciatura devem preparar os futuros profissionais para o contexto de dificuldades estruturais que ultrapassam as questões práticas internas às salas de aula, as metodologias de ensino e a burocracia escolar. A consciência crítica a ser construída durante a graduação deve possibilitar o enfrentamento de desafios inerentes ao contexto da profissão docente, que seja resistente tanto às dificuldades mais rotineiras e mais imediatas da Educação Básica, quanto às representações socioculturalmente construídas sobre as possibilidades e limites do trabalho docente, a importância e a abrangência deste na sociedade contemporânea.

Os resultados deste trabalho remetem, ainda, a um terceiro ponto: o desafio de superar uma visão essencialmente técnica para a formação docente (modelo conhecido como racionalidade técnica, que segmenta o aprendizado teórico do prático) e promover ações que contemplem o modelo da racionalidade prática para a formação dos sujeitos, tendo em vista o desenvolvimento de identidades docentes que sejam sensíveis aos múltiplos saberes necessários para exercer o magistério (NÓVOA, 2009; FONSECA; SANTOS, 2018). Ora, se está visível que este estudo se debruça sobre os processos de aprendizagem no estágio de docência (destacando as interações de um estudante de licenciatura com aspectos práticos da docência), as análises realizadas convergem com a premissa de que esse momento formativo não pode ser pensado como simples aplicação de técnicas pedagógicas, mas como oportunidade de diálogo entre teoria e prática, entre saber e saber fazer, entre o ambiente universitário/ formador e o ambiente escolar/ realidade da futura profissão (LIMA, 2001; FELÍCIO; OLIVEIRA, 2008).

\section{Considerações Finais}

Infere-se que o trabalho ora apresentado atingiu os objetivos que foram propostos: foi possível identificar e problematizar algumas das vivências e aprendizagens construídas pelo professor-estagiário (autor do relatório que foi investigado). Os resultados da análise de conteúdo do texto da fonte documental permitiu a identificação de quatro grandes momentos de construção de saberes: observações do espaço escolar, estudo de referenciais teóricos (destinados a serem articulados com as práticas docentes), regência de classe e construção de reflexões pessoais sobre o trabalho na sala de aula (relacionamentos, aspectos pedagógicos etc.).

Nas observações do espaço escolar, ficou claro que o professor em formação conseguiu entrar em contato com diferentes fatores, citados por Tardif (2002), que embasam a rotina de trabalho no magistério (fatores materiais e ambientais; fatores sociais e econômicos; elementos que determinam a organização do trabalho e os relacionamentos entre os pares). No que tange 
aos momentos de estudo sobre os aspectos teóricos educacionais, principalmente desenvolvidos em articulação com os encontros na universidade, foi possível perceber movimentos de convergência do estagiário com referenciais contemporâneos para a prática pedagógica dos professores de Química, principalmente envolvendo material didático, avaliação e modelos de ensino de Ciências da Natureza, com atenção especial às perspectivas construtivistas e CTS (FERNANDES; MEGID-NETO, 2012). Houve evidências, inclusive, de atributos desses modelos nos planejamentos de aulas propostos para o período de estágio.

Os dados analisados mostram que, com a regência de classe, o professor em formação vivenciou satisfatoriamente o contato com algumas das características da profissão docente relacionadas ao que Nóvoa (2009) considera como dimensões necessárias para pensar o contexto de trabalho do profissional do magistério: conhecimento do que está ensinando, tato pedagógico e articulação da teoria com a prática educacional. Por outro lado, não há evidências mais concretas de que tenham ocorrido apropriações de conhecimentos e práticas profissionais da docência relacionadas à cultura profissional mais global (contato com professores da Educação Básica externos à área de Química), ao trabalho em equipe e ao compromisso social.

Pelo que foi exposto, conclui-se que há indícios de que o estágio investigado tenha cumprido sua função formadora, promovendo aprendizagens relevantes sobre o trabalho do professor de Química do ensino médio, bem como oportunizando momentos de reflexão fundamentais para a constituição de um perfil profissional eficiente, que consiga dialogar com as próprias ações, diante dos conflitos e dificuldades surgidas na complexidade da sala de aula (SCHÖN, 1983, 1995). Pensando-se na organização de temas para futuras pesquisas, este trabalho contribui com a apresentação de resultados e reflexões com algumas especificidades referentes ao contexto imediato (escola, estagiário, discentes, curso de licenciatura, fonte de dados etc.).

Nesse sentido, alguns questionamentos podem ser explorados em próximas investigações, tais como: qual seria a influência da carga horária do estágio para o aprofundamento teóricoprático do sujeito, considerando-se que há outros momentos da trajetória curricular do curso nos quais ocorrem interações com as escolas? Que outras formas de coleta de dados poderiam enriquecer as informações fornecidas pelo relatório, tornando a investigação mais complexa: entrevistas com os estagiários, com estudantes do ensino médio interpelados pelo estagiário, com funcionários da escola ou, ainda, observação direta de aulas ministradas pelo professor em \# Tear: Revista de Educação Ciência e Tecnologia, Canoas, v.8, n.1, 2019. 
formação? Além do relatório de estágio, que outros instrumentos de avaliação têm sido utilizados por orientadores de estágio e em que extensão ocorre a presença destes no âmbito da literatura contemporânea da área educacional? Quais seriam os limites da influência do perfil do orientador de estágio nas vivências e aquisições de conhecimento construídas pelos aprendizes?

As dúvidas acima, possivelmente, despertam motivos para que as investigações acadêmicas sobre os estágios de docência continuem sendo pauta de diferentes círculos universitários do país. Infere-se, assim, que este trabalho contribuiu com o rol de pesquisas que problematizam o modelo da racionalidade prática para a formação de professores (da área de Ciências da Natureza, em especial), reforçando a defesa de que esta se constitui como uma opção viável e imprescindível para que os cursos de licenciatura consigam oportunizar procedimentos de ensino-aprendizagem adequados, que norteiem, com solidez, a vida profissional de seus egressos.

\title{
CHEMISTRY TEACHING INTERNSHIP: A DOCUMENTAL STUDY ON THE CONSTRUCTION OF PROFESSIONAL KNOWLEDGE IN BASIC EDUCATION.
}

\begin{abstract}
This work seeks to report and problematize the learning resulting from the actions of a trainee teacher, within the framework of a teaching activity of the Teaching degree in Chemistry program of the Federal University of Rio Grande do Sul taking as main theoretical references the ideas of authors such as Tardif and Novoa. The internship was supervised and carried out in a state public school in the capital of Rio Grande do Sul in two high school classes. This is a qualitative exploratory study based on a single documental source (the final report produced by the trainee) so that the content analysis of the textual production aforementioned was carried out. The results point to the occurrence of four formative movements of great importance for the construction of professional knowledge: observations of the school space (material, social, environmental, economic factors, among others), study of theoretical references (involving teaching materials, assessments, troubleshooting and models of teaching of natural sciences), class regency and construction of personal reflections of the teacher-trainee on the work in the classroom (including aspects such as: knowledge about the contents to be worked, pedagogical tact and relationship between theory and practice). Thus, different learnings by the trainee teacher deriving from his work in Basic Education were verified as well as the data analyzed reinforced the relevance of the adoption of traineeship reports as documental source of researches that focus on the initial teacher training.
\end{abstract}

Keywords: Teacher training. Teaching internship. Chemistry teaching. Teaching knowledge. 


\section{Referências}

ALMEIDA, P. C. A. de; BIAJONE, J. Saberes docentes e formação inicial de professores: implicações e desafios para as propostas de formação. Educação e Pesquisa, v. 33, n. 2, p. 281295, 2007.

BACH, M. F.; FONSECA, C. V. Aprendizagem baseada em problemas envolvendo a temática alimentação: reflexões decorrentes de um estágio em ensino de química. Tear: Revista de Educação, Ciência e Tecnologia, v. 7, n. 2, p. 1-20, 2018.

BARCELOS, N. N. S.; VILLANI, A. Troca entre universidade e escola na formação docente: uma experiência de formação inicial e continuada. Ciência \& Educação, v.12, n.1, p. 73-97, 2006.

BEJARANO, N. R. R.; CARVALHO, A. M. P. de. Tornando-se professor de ciências: crenças e conflitos. Ciência \& Educação, v.9, n.1, p. 1-15, 2003.

BRASIL. Presidência da República. Lei no 11.788, de 25 de setembro de 2008. Brasília, 2008.

BROIETTI, F. C. D.; BARRETO, S. R. G. Formação inicial de professores de química: a utilização dos relatórios de observação de aulas como instrumentos de pesquisa. Semina: Ciências Exatas e Tecnológicas, v.32, n.2, p. 181-190, 2011.

CAMARGO, E. P. de; NARDI, R. Dificuldades e alternativas encontradas por licenciandos para o planejamento de atividades de ensino de óptica para alunos com deficiência visual. Revista Brasileira de Ensino de Física, v.29, n.1, p. 115-126, 2007.

DINIZ-PEREIRA, J. E. A Pesquisa dos Educadores como estratégia para construção de modelos críticos de formação docente. In: Diniz-Pereira, J. E.; Zeichner, K. M. A (orgs.). Pesquisa na Formação e no Trabalho Docente. Belo Horizonte: Autêntica, 2002. 200 p.

FELÍCIO, H. M. dos; OLIVEIRA, R. A. A formação prática de professores no estágio curricular. Educar em Revista, v. 32, p. 215-232, 2008.

FERNANDES, R. C. A. F.; MEGID-NETO, J. Modelos educacionais em 30 pesquisas sobre práticas pedagógicas no ensino de ciências nos anos iniciais da escolarização. Investigações em Ensino de Ciências, v.17, n.3, p. 641-662, 2012.

FONSECA, C. V. A formação de professores de química em instituições de ensino superior do Rio Grande do Sul: saberes, práticas e currículos. Tese de Doutorado, Faculdade de Educação, Programa de Pós-Graduação em Educação, Universidade Federal do Rio Grande do Sul, Porto Alegre, 2014.

FONSECA, C. V.; SANTOS, F. M. T. O curso de licenciatura em química da UFRGS: estudo da estrutura curricular e de aspectos constitutivos da formação docente. Alexandria: Revista de Educação em Ciência e Tecnologia, v.8, n.3, p. 81-111, 2015. 


\section{\#tear}

FONSECA, C. V.; SANTOS, F. M. T. Educação em química, formação e trabalho docente: revisão de pesquisas brasileiras (2002-2015). Investigações em Ensino de Ciências, v. 21, n.2, p. 179-199, 2016.

FONSECA, C. V.; SANTOS, F. M. T. Diferentes olhares sobre as práticas pedagógicas na Licenciatura em Química: um estudo de caso. Tear: Revista de Educação, Ciência e Tecnologia, v. 7, n.1, p. 1-18, 2018.

FRANCO, M. L. P. B. Análise de Conteúdo. 3. ed. Brasília: Líber Livro Editora, 2008. 80 p.

GIANOTTO, D. E. P.; DINIZ, R. E. da S. Formação inicial de professores de Biologia: a metodologia colaborativa mediada pelo computador e a aprendizagem para a docência. Ciência \& Educação, v.16, n.3, p. 631-648, 2010.

HILA, C. V. D. O gênero artigo de opinião: diagnóstico e intervenção na formação inicial de professores de português. Trabalhos em Linguística Aplicada, v.47, n.1, p. 183-201, 2008.

LEMOS, P. S.; SÁ, L. P. A avaliação da aprendizagem na concepção de professores de química do ensino médio. Revista Ensaio, v.15, n.3, p. 53-71, 2013.

LIMA, M. S. L. A hora da prática: reflexões sobre o estágio supervisionado e ação docente. 2. ed. Fortaleza: Edições Demócrito Rocha, 2001.

LÜDKE, M.; ANDRÉ, M. Pesquisa em educação: abordagens qualitativas. São Paulo: EPU, 1986.

NÓVOA, A. Professores: Imagens do Futuro Presente. Lisboa: Educa, 2009.

PINHEIRO, A. N.; MEDEIROS, E. de L.; OLIVEIRA, A. C. Estudo de casos na formação de professores de química. Química Nova, v.33, n.9, p.1996-2002, 2010.

PRATES-JUNIOR, M. S. L.; SIMÕES-NETO, J. E. Situações-problema com Estratégia Didática para o Ensino dos Modelos Atômicos. Revista Brasileira de Ensino de Ciência e Tecnologia, v.8, n.2, p. 181-201, 2015.

RODRIGUES, M. A.; ARROIO, A. Pesquisa no estágio supervisionado: alguns resultados e muitas possibilidades. Alexandria, v. 11, p. 31-49, 2018.

ROSA, . R. T. D; VEIT, M. H. D. Estágio Docente: análise de interações sociais em sala de aula. Educação \& Realidade, Porto Alegre, v.36, n.1, p. 295-316, 2011.

SANTOS, F.M.T. Unidades Temáticas - produção de material didático por professores em formação inicial. Experiências em Ensino de Ciências, v.2, n.1, p. 1-11, 2007.

SCHÖN, D. The Reflective Practioner. New York: Basic Books, 1983.

\# Tear: Revista de Educação Ciência e Tecnologia, Canoas, v.8, n.1, 2019. 
SCHÖN, D. Formar Professores como Profissionais Reflexivos. In: Nóvoa, A. (Coord.). Os professores e a sua formação. 2.ed. Lisboa: Dom Quixote / Instituto de Inovação Educacional, 1995.

SILVA, L. F.; CARVALHO, L. M. de. A temática ambiental e as diferentes compreensões dos professores de física em formação inicial. Ciência \& Educação, v.18, n.2, p. 369-383, 2012.

SILVA, K. C. M. O.; MESQUITA, N. A. S. Práxis e identidade docente: entrelaces no contexto da formação pela pesquisa na licenciatura em química. Química Nova na Escola, v. 40, p. 4452, 2018.

TARDIF, M. Saberes docentes e formação profissional. 3. ed. Petrópolis: Vozes, 2002.

TARDIF, M.; LESSARD, C. O Trabalho Docente: elementos para uma teoria da docência como profissão de interações humanas. 4. ed. Petrópolis: Vozes, 2008. 